\title{
PERENCANAAN EKSPERIMEN PADA PROSES EDM UNTUK MENGURANGI KEAUSAN ELEKTRODA
}

\section{EXPERIMENTAL PLANNING IN EDM PROCESS FOR REDUCING ELECTRODE WEARNESS}

\author{
Sony Harbintoro, Agus Suherman, Darwin Rachman GM, Luky Krisnadi \\ Balai Besar Logam dan Mesin, Jalan Sangkuriang No.12 Bandung 40135 \\ Email: sony-harbintoro@kemenperin.go.id
}

\begin{abstract}
Abstrak
Proses Electric Discharge Machine (EDM) merupakan teknologi pemotongan logam nontradisional yang menggunakan energi panas pada proses pemotongannya. Proses EDM banyak digunakan pada pembuatan komponen core cavity cetakan/mold. Biaya pembuatan elektroda untuk mendukung proses EDM merupakan salah satu biaya yang harus diperhitungkan dalam proses EDM, sehingga mengurangi keausan elektroda menjadi hal yang penting karena dapat menekan biaya pembuatan elektroda. Pada penelitian ini, proses EDM menggunakan elektroda yang mempunyai profil dengan ketebalan $2 \mathrm{~mm}$ serta panjang $30 \mathrm{~mm}$ yang digunakan untuk membuat profil pocket sedalam $26 \mathrm{~mm}$. Permasalahan yang ditemui pada proses EDM dengan menggunakan profil elektroda yang tipis yaitu umur pemakaian elektroda yang cepat aus pada bagian ujung dari elektroda. Hal ini akan menyebabkan elektroda menjadi boros dan berpengaruh terhadap biaya pembuatan elektroda. Untuk memperpanjang umur pemakaian elektroda dan menekan biaya pembuatan elektroda, maka diperlukan strategi setting parameter yang sesuai pada proses EDM. Setting parameter pada proses EDM dengan elektroda yang tipis yaitu diantaranya pengaturan parameter arus, $T_{o n}$ dan $T_{\text {off }}$. Berdasarkan hasil eksperimen untuk memperpanjang umur pemakaian elektroda, maka strategi proses EDM yang dilakukan yaitu (1) pada proses roughing pada kedalaman 0 s.d. $24 \mathrm{~mm}$ menggunakan parameter ampere $8 A ; T_{\text {on }} 20 \mu \mathrm{s} ; T_{\text {off }} 10 \mu \mathrm{s}$. (2) Proses finishing pada kedalamam $24 \mathrm{~mm}$ s.d. $26 \mathrm{~mm}$, menggunakan parameter ampere $6 A ; T_{o n} 3 \mu \mathrm{s}, T_{\text {off }} 4 \mu \mathrm{s}$. Dengan menggunakan strategi dua parameter pada kedalaman berbeda, dapat mengurangi keausan elektroda dan memperpanjang umur penggunaan elektroda.
\end{abstract}

Kata kunci: EDM, elektroda, keausan, cetakan

\begin{abstract}
Process of Electric Discharge Machine (EDM) is a non-traditional metal cutting technology that uses heat energy in the cutting process. The EDM process is widely used in the making of mold core cavity components. The cost of making electrodes to support the EDM process is one of the costs that must be taken into account in the EDM process, so reducing the wear of electrodes is important because it can reduce the cost of making electrodes. In this study, the EDM process uses electrodes that have a profile with a thickness of $2 \mathrm{~mm}$ and a length of $30 \mathrm{~mm}$ which is used to make a pocket profile as deep as $26 \mathrm{~mm}$. Problems encountered in the EDM process by using a thin electrode profile are the age of use at which electrodes wear quickly at the tip of the electrode. This will cause the electrode to become wasteful and affect the cost increase for electrodes making. To extend the age of use the electrode and reduce the cost of making electrodes, the appropriate parameter setting strategy is needed in the EDM process. Parameter settings in the EDM process with thin electrodes which include current parameter settings, $T_{\text {on }}$ and $T_{\text {off. }}$ Based on the experimental results to extend the age of use the electrode, the EDM process strategy is carried out, namely (1) in the roughing process at a depth of $0-24 \mathrm{~mm}$ using the $8 \mathrm{~A}$ ampere parameter; $T_{\text {on }}$ of $20 \mu \mathrm{s} ; T_{\text {off }} 10 \mu \mathrm{s}$. (2) The finishing process is 24 - $26 \mathrm{~mm}$, using the $6 \mathrm{~A}$ ampere parameter; $T_{\text {on }}$ of $3 \mu \mathrm{s}, T_{\text {off }} 4 \mu \mathrm{s}$. Using a two-parameter strategy at different depths, it can reduce electrode wear and extend the age of use electrode.
\end{abstract}




\section{PENDAHULUAN}

Electric Discharge Machine (EDM) merupakan teknologi pemotongan logam nontraditional yang menggunakan energi panas pada proses pemotongannya (thermal cutting processes). Proses EDM adalah proses pengerjaan material oleh sejumlah loncatan bunga api listrik (spark) yang terjadi pada celah di antara elektroda dengan benda kerja. Loncatan bunga api listrik terjadi secara periodik terhadap waktu. Pada proses EDM digunakan cairan dielektrik (dielectric fluid), yang berada diantara elektrode dengan benda kerja (Rajmohan T., et.al. 2012).

Saat ini perubahan inovasi di bidang proses pemesinan non-tradisional tidak dianggap sebagai pengganti metode pemesinan konvensional pada pengerjaan logam. Proses pemesinan non-tradisional menawarkan solusi alternatif untuk aplikasi proses pemesinan (Patel 2014). Teknologi EDM makin banyak digunakan pada industri manufaktur untuk pembuatan cetakan (mold \& dies) dan proses pemesinan untuk material yang sangat kuat dan keras seperti tool steel (Shailesh Kumar Dewangan 2010) . Hasil dari proses EDM menghasilkan produk yang mempunyai kepresisian yang tinggi, dapat mengerjakan bentuk/profil yang rumit, serta kualitas permukaan yang baik (Risto, Haas, and Munz 2016). Proses EDM cocok untuk pengerjaan produk core cavity pada cetakan (mold \& dies). Dimana sifat material yang digunakan untuk core cavity pada cetakan (mold \& dies) harus mempunyai sifat-sifat mekanik seperti ketahanan tempering yang baik, hot yield strenght yang tinggi, dan ketangguhan yang baik.

Proses EDM menghasilkan kualitas permukaan benda kerja yang baik, terdapat beberapa variabel proses yang mempengaruhi integritas permukaan seperti lama pengerjaan (work time), kuat arus, tegangan, polaritas elektroda, propertis material elektroda, cairan dielektrik, dan ukuran elektroda (Risto, Haas, and Munz 2016).

Beberapa parameter penting dalam proses EDM yaitu setting arus (ampere), $T_{\text {on }}$ dan $T_{\text {off }}$ yang akan mempengaruhi waktu proses machining. Setting besarnya arus, $T_{\text {on }}$ dan $T_{\text {off }}$ pada mesin EDM mempengaruhi hasil akhir permukaan benda kerja dalam proses EDM
(Fan et al. 2016). Variasi dari besarnya arus, $T_{o n}$ dan $T_{\text {off }}$ pada proses EDM akan mengakibatkan perbedaan kekasaran (surface roughness) pada benda kerja serta akan menentukan keausan pada elektroda yang digunakan.

Besar kecilnya arus dan lama durasi percikan bunga api listrik yang terjadi saat proses discharge akan mempengaruhi temperatur termal yang terjadi. Semakin besar percikan bunga api listrik (spark) yang terjadi akan mengakibatkan peningkatan temperatur pada saat proses pengikisan. Perbedaan dan perubahan temperatur juga akan mengakibatkan perbedaan di setiap lapisan pada material yang diproses. Perubahan temperatur proses EDM akan berdampak pada perubahan kekerasan material yang diproses. Gradien temperatur pada proses discharge akan terus menurun dari pusat percikan menuju ke samping percikan (Zhang et al. 2016). Suhu tertinggi berada pada titik pusat percikan dimana pada daerah tersebut terjadi penguapan.

Proses EDM dilakukan dengan sebuah sistem yang mempunyai dua komponen pokok yaitu perangkat keras mesin dan power supply (Guo and Ling 2016). Perangkat keras mesin mengontrol mekanisme elektroda yang bergerak mengikis material benda kerja dan menghasilkan bunga api listrik yang berfrekuensi tinggi (spark). Loncatan bunga api dihasilkan dari generator power supply pembangkit pulse antara elektroda yang bermuatan negatif dan benda kerja yang bermuatan positif. Pada proses EDM, elektroda dan benda kerja direndam dalam cairan dielektrik (EDM oil).

Pada proses EDM, laju pengikisan material benda kerja atau material removal rate (MRR) pada operasi EDM lebih lambat dibandingkan metode pemesinan tradisional yang menghasilkan chips secara mekanis. Pada proses EDM, laju pengikisan material sangat tergantung dari faktor-faktor seperti besarnya arus disetiap muatan, frekuensi muatan, material elektroda, material benda kerja, kondisi flushing, dan cairan dielektrik yang digunakan.

Keausan elektroda berupa pengikisan dapat terjadi selama proses operasi EDM, dimana elektroda sebagai tool akan ter-erosi sebagai akibat dari loncatan bunga api (Li et al. 
2014). Laju pengikisan material elektroda harus lebih kecil dibandingkan dengan pengikisan yang terjadi pada material benda kerja, hal itu dimaksudkan untuk mengurangi biaya pembuatan elektroda. Dengan makin tingginya arus maka laju erosi akan makin meningkat yang akan menghasilkan laju pengikisan material (MRR) pada elektroda dan benda kerja yang lebih tinggi. Kecepatan proses pengikisan dan kekasaran permukaan akhir dari benda kerja akan tergantung dari parameter arus, frekuensi, dan intensitas bunga api yang terjadi.

Tujuan penelitian ini yaitu untuk menentukan setting parameter proses EDM untuk menekan biaya pembuatan elektroda dengan mengurangi keausan elektroda, pada proses EDM pembuatan profil pocket di core cavity cetakan/mold sedalam $26 \mathrm{~mm}$, dengan elektroda yang mempunyai profil ketebalan 2 $\mathrm{mm}$ serta panjang $30 \mathrm{~mm}$. Manfaat penelitian ini yaitu dengan mengurangi laju MRR (material removal rate) pada elektroda, dapat menekan biaya pembuatan elektroda dan dapat mengurangi biaya proses EDM secara keseluruhan. Peningkatan teknologi proses sangat dibutuhkan pada proses EDM die sinker khususnya untuk menentukan parameter proses yang sesuai agar dapat mengurangi keausan elektroda.

\section{METODOLOGI}

Penelitian dilakukan pada tahun 2018 di salah satu instansi litbang yang memiliki fasilitas mesin EDM die sinker. Pada penelitian ini digunakan bahan sebagai objek penelitian. Pada Tabel 1 diuraikan mengenai bahan penelitian yang digunakan.

Tabel 1. Bahan untuk benda kerja dan elektroda

\begin{tabular}{|c|l|l|c|}
\hline No & Komponen & Material & Ukuran (mm) \\
\hline 1 & $\begin{array}{l}\text { Benda } \\
\text { kerja }\end{array}$ & S45C & $200 \times 200 \times 60$ \\
\hline 2 & Elektroda & Tembaga & $100 \times 100 \times 10$ \\
\hline 3 & Baut & & M 8 50 mm \\
\hline 3 & $\begin{array}{l}\text { Dielectric } \\
\text { fluid }\end{array}$ & kerosene & 200 liter \\
\hline
\end{tabular}

Mesin dan peralatan yang digunakan pada penelitian ini dapat dilihat pada Tabel 2.
Tabel 2. Alat yang digunakan

\begin{tabular}{|c|l|l|}
\hline No & \multicolumn{1}{|c|}{ Alat } & \multicolumn{1}{c|}{ Spesifikasi } \\
\hline 1 & $\begin{array}{l}\text { Mesin EDM die } \\
\text { sinker }\end{array}$ & $\begin{array}{l}\text { Travel 300 x 400 x } \\
300 \mathrm{~mm}\end{array}$ \\
\hline 2 & Magnetic table & Dia. $200 \mathrm{~mm}$ \\
\hline 3 & Dial indicator & $0.01 \mathrm{~mm}$ \\
\hline 4 & Superglue & \\
\hline 5 & Hexagon keys & $1,5-10 \mathrm{~mm}$ \\
\hline
\end{tabular}

Tahapan Penelitian

Untuk mendukung pelaksanaan kegiatan perencanaan eksperimen pada proses EDM untuk mengurangi keausan elektroda maka dilakukan beberapa persiapan sebagai berikut :

1. Mempersiapkan bahan (workpiece dan elektroda) serta mesin dan peralatan sesuai Tabel 1 dan Tabel 2.

2. Membuat jadwal pelaksanan kegiatan

3. Membuat urutan proses pekerjaan dengan membuat gambar teknis dan formulir kartu kerja.

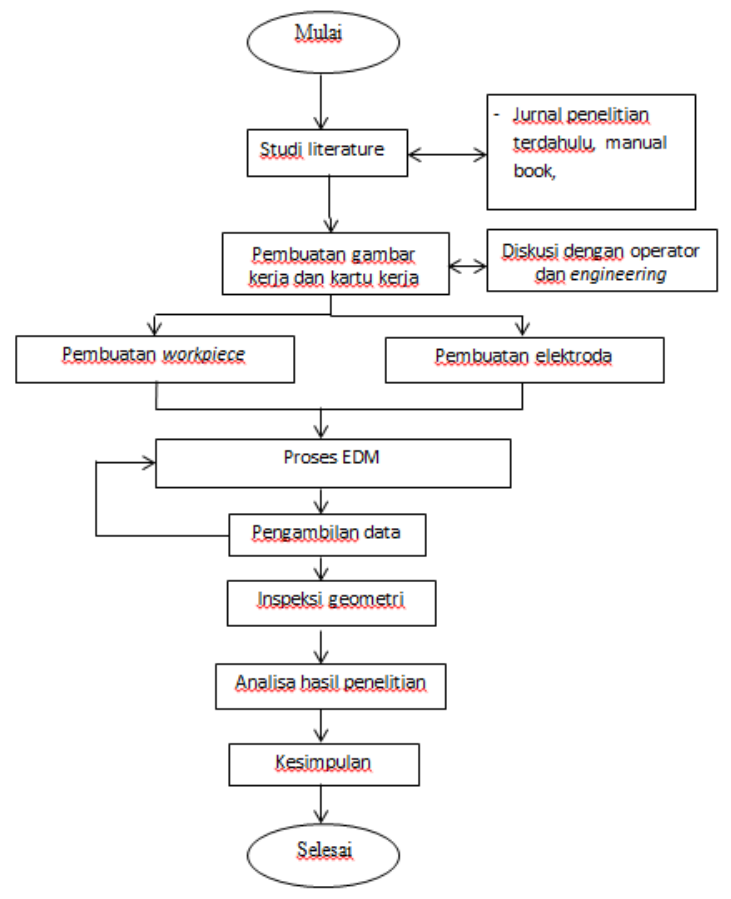

Gambar 1. Diagram alir penelitian

Proses pembuatan gambar kerja dilakukan dengan berkoordinasi dengan operator mesin EDM serta bagian engineering untuk mendapatkan saran dan masukan mengenai profil elektroda yang akan dibuat. Pada kartu kerja pembuatan elektroda telah ditentukan parameter mesin untuk membuat elektroda pada mesin CNC milling sebelum dipasang pada mesin EDM. 
Proses EDM dilakukan setelah pembuatan workpiece dan elektroda telah selesai dilakukan. Proses pengambilan data dilakukan dengan mengatur parameter arus (ampere), $T_{\text {on }}$ dan $T_{\text {off. }}$ Dari hasil pengumpulan data akan dianalisis besaran ampere serta duty cycle yang paling sesuai terhadap pengurangan keausan elektroda.

\section{HASIL DAN PEMBAHASAN}

Pembuatan elektroda yang akan digunakan pada mesin EDM merupakan salah satu bagian penting yang akan mempengaruhi hasil akhir dari geometri benda kerja (workpiece). Waktu proses pembuatan elektroda di penelitian ini menggunakan mesin CNC milling yang diperlihatkan pada Tabel 3 .

Tabel 3. Waktu pembuatan elektroda

\begin{tabular}{|c|l|c|}
\hline No & $\begin{array}{l}\text { Urutan proses dan cutting tools } \\
\text { yang digunakan }\end{array}$ & $\begin{array}{c}\text { Waktu } \\
\text { (menit) }\end{array}$ \\
\hline 1 & $\begin{array}{l}\text { Setting elektroda pada ragum } \\
\text { mesin }\end{array}$ & 15 \\
\hline 2 & $\begin{array}{l}\text { Facing menggunakan Endmill } \\
\varnothing 8 \text { mm }\end{array}$ & 40 \\
\hline 3 & $\begin{array}{l}\text { Facing menggunakan Ballnose } \\
\text { Ø } 4 \text { mm }\end{array}$ & 39 \\
\hline 4 & $\begin{array}{l}\text { Facing menggunakan Endmill } \\
\varnothing 4 \text { mm }\end{array}$ & 9 \\
\hline 5 & $\begin{array}{l}\text { Facing menggunakan Endmill } \\
\varnothing 6 \text { mm }\end{array}$ & 10 \\
\hline 6 & $\begin{array}{l}\text { Facing menggunakan Endmill } \\
\varnothing 8 \text { mm }\end{array}$ & 47 \\
\hline 7 & $\begin{array}{l}\text { Facing menggunakan Ballnose } \\
\varnothing 4 \text { mm }\end{array}$ & 19 \\
\hline 8 & $\begin{array}{l}\text { Facing menggunakan Endmill } \\
\varnothing 4 \text { mm }\end{array}$ & 5 \\
\hline 9 & $\begin{array}{l}\text { Facing menggunakan Endmill } \\
\varnothing 6 \text { mm }\end{array}$ & 10 \\
\hline 10 & $\begin{array}{l}\text { Elektroda dipotong menjadi } 6 \\
\text { buah menggunkan Gergaji }\end{array}$ & 18 \\
\hline 11 & $\begin{array}{l}\text { Membuat } \\
\text { menggunakan Drill Ø 6,8 mm }\end{array}$ & 48 \\
\hline 12 & $\begin{array}{l}\text { Pembuatan ulir menggunakan } \\
\text { Tap M 8 mm }\end{array}$ & 26 \\
\hline 13 & \begin{tabular}{l} 
Pemasangan tangkai elektroda \\
\hline
\end{tabular} & 20 \\
\hline Total waktu & 306 \\
\hline
\end{tabular}

Dari hasil pengumpulan data waktu total waktu pembuatan elektroda membutuhkan waktu 306 menit. Pada proses penelitian ini dilakukan dengan membuat 6 elektroda dengan dimensi geometri yang sama. Sehingga waktu setiap pembuatan elektroda yaitu 51 menit. Untuk mempercepat waktu pembuatan maka proses pengerjaan profil elektroda dibuat secara langsung pada mesin CNC milling kemudian dibagi menjadi 6 bagian elektroda. Setiap elektroda akan dipasangi dengan tangkai pemegang elektroda agar bisa dicekam pada electrode chuck di mesin EDM. Pemasangan tangkai pemegang elektroda menggunakan baut M8 panjang $50 \mathrm{~mm}$, dengan menggunakan superglue agar dipastikan posisi elektroda terhadap tangkai/poros pemegang tidak berubah. Pada Gambar 2 ditunjukan posisi tangkai pemegang pada electrode chuck mesin EDM.

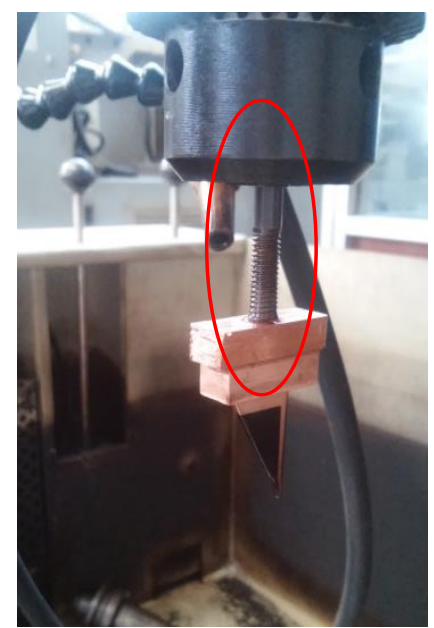

Gambar 2. Posisi pemegang elektroda pada electrode chuck mesin EDM

Pada Gambar 3. Ditunjukan elektroda terbuat dari material tembaga yang dibuat dengan mesin CNC milling. Elektroda yang dibuat mempunyai ketebalan $2 \mathrm{~mm}$, sehingga memiliki tingkat kesulitan yang cukup tinggi pada saat setting elektroda terhadap benda kerja serta penentuan parameter proses EDM. 


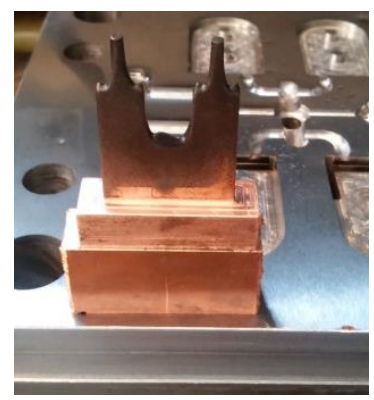

Gambar 3. Elektroda tembaga

Kondisi pada mesin EDM saat digunakan untuk penelitian ditunjukan pada Tabel 4.

Tabel 4. Kondisi mesin EDM saat penelitian

\begin{tabular}{|l|l|}
\hline \multicolumn{2}{|c|}{ Spesifikasi } \\
\hline Table size $($ WxD $)$ & $650 \times 400 \mathrm{~mm}$ \\
\hline Work tank size $(W x D \times H)$ & $1050 \times 630 \times 350 \mathrm{~mm}$ \\
\hline Table travel $(X, Y)$ & $400 \times 300 \mathrm{~mm}$ \\
\hline Ram travel $(\mathrm{Zl})$ & $350 \mathrm{~mm}$ \\
\hline $\begin{array}{l}\text { Distance from RAM } \\
\text { platen to work table }\end{array}$ & $305 \sim 655 \mathrm{~mm}$ \\
\hline Max. electrode weight & $100 \mathrm{~kg}$ \\
\hline Max. workpiece weight & $1000 \mathrm{~kg}$ \\
\hline Flushing dielectric & $\begin{array}{l}\text { Side flushing with } \\
\text { pressure }\end{array}$ \\
\hline Ampere & 75 ampere \\
\hline
\end{tabular}

Sumber : (CHMER 2012)

Kedalaman pembuatan pocket dengan proses EDM yaitu $26 \mathrm{~mm}$, dimana elektroda yang digunakan dengan tebal $2 \mathrm{~mm}$ berbentuk U. Proses setting parameter dilakukan pada saat proses EDM. Setting parameter pada percobaan yang pertama ditunjukan pada Tabel 5 .

Tabel 5. Parameter percobaan pertama

\begin{tabular}{|l|l|}
\hline \multicolumn{2}{|c|}{ Parameter } \\
\hline Ampere & $8 \mathrm{~A}$ \\
\hline Jog time & $0,8 \mathrm{~mm}$ \\
\hline Work time & $0,8 \mathrm{~second}$ \\
\hline$T_{\text {on }}$ & $20 \mu \mathrm{s}$ \\
\hline$T_{\text {off }}$ & $10 \mu \mathrm{s}$ \\
\hline
\end{tabular}

Dengan parameter mesin seperti pada Tabel 5, maka didapat duty cycle serta frekuensi pada percobaan 1.

Duty cycle adalah persentase dari waktu relative $T_{\text {on }}$ terhadap total waktu siklus. Duty cycle yang lebih tinggi akan meningkatkan efisiensi pemotongan.

perhitungan duty cycle yaitu :
Duty cycle $=\frac{\text { on-time }(\mu s)}{\text { Total Cycle Time }(\mu s)} \times 100 \%$

(1)

$$
\begin{gathered}
\text { Duty cycle }=\frac{20 \mu s}{20 \mu s+10 \mu s} \times 100 \% \\
=66.6 \%
\end{gathered}
$$

Frekuensi adalah jumlah siklus yang dihasilkan di celah/gap dalam satu detik. Semakin tinggi frekuensi, semakin halus permukaan akhir yang dapat diperoleh. Hasil akhir yang diperoleh akan lebih halus dengan sedikit kerusakan termal pada benda kerja. Frekuensi rendah umumnya digunakan untuk operasi roughing. Waktu yang lebih panjang menciptakan celah yang lebih dalam dan lebih luas, sehingga membuang lebih banyak material. Frekuensi rendah pada saat proses roughing memungkinkan lebih banyak panas pada elektroda dan benda kerja yang berarti lapisan recast akan lebih tebal dan zona yang terkena panas (heat affected zone) akan lebih dalam.

Perhitungan frekuensi :

$$
\begin{gathered}
\text { Frekuensi }(\mathrm{kHz})=\frac{1000}{\text { Total Cycle Time }(\mu \mathrm{s})}(2) \\
\text { Frekuensi }=\frac{1000}{20 \mu \mathrm{s}+10 \mu \mathrm{s}}=33.3 \mathrm{kHz}
\end{gathered}
$$

Dengan menggunakan parameter ini, proses EDM roughing dilakukan. Pada percobaan pertama ini, elektroda yang digunakan mengalami kerusakan pada ujung elektroda sehingga elektroda perlu diganti.

Gambar 4 menunjukan ujung elektroda yang patah sebagai akibat dari ampere yang besar dan frekuensi yang rendah.

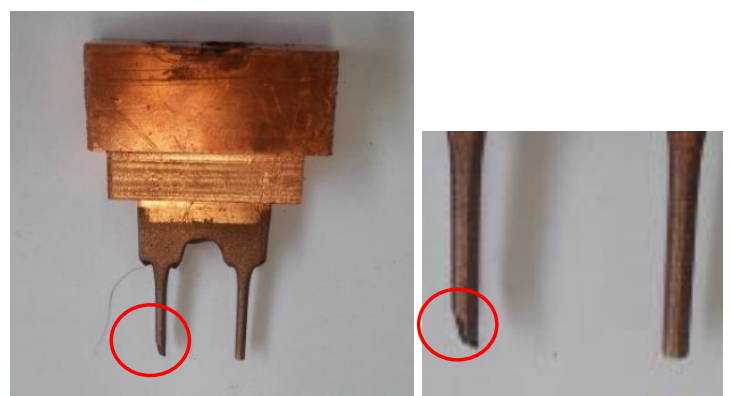

Gambar 4. Kerusakan elektroda pada percobaan pertama 
Percobaan kedua dilakukan dengan mengurangi besaran ampere serta $T_{\text {on }}$ dan $T_{\text {off }}$ dimaksudkan agar umur pemakaian elektroda menjadi lebih lama.

Tabel 6. Parameter percobaan kedua

\begin{tabular}{|l|l|}
\hline \multicolumn{2}{|c|}{ Parameter } \\
\hline Ampere & $6 \mathrm{~A}$ \\
\hline Jog time & $2.0 \mathrm{~mm}$ \\
\hline Work time & 1,2 second \\
\hline$T_{\text {on }}$ & $3 \mu \mathrm{s}$ \\
\hline$T_{\text {off }}$ & $4 \mu \mathrm{s}$ \\
\hline
\end{tabular}

Berdasarkan parameter percobaan kedua, maka dapat dihitung :

$$
\text { Duty cycle }=\frac{3 \mu s}{3 \mu s+4 \mu s} \times 100 \%=42.8 \%
$$

Sedangkan perhitungan frekuensi:

$$
\text { Frekuensi }=\frac{1000}{3 \mu s+4 \mu s}=142.8 \mathrm{kHz}
$$

Pada percobaan kedua, duty cycle lebih lama dari pada waktu percobaan pertama sehingga waktu proses EDM menjadi lebih lama, namun umur pakai elektrode menjadi lebih lama. Frekuensi pada percobaan kedua lebih tinggi dari percobaan pertama sehingga dikategorikan finishing.

Dari data percobaan yang telah dilakukan, maka dilaksanakan strategi proses EDM dengan menggunakan srtategi dua parameter proses. Strategi proses EDM yang dilakukan dengan cara mengubah setting ampere, $T_{\text {on }}$ dan $T_{\text {off }}$ sesuai kedalaman pocket yang akan dibuat. Perubahan setting parameter proses tersebut dimaksudkan untuk menghindari kerusakan pada ujung elekroda pada saat machining di kedalaman $\geq 24 \mathrm{~mm}$. Pada kedalaman $24 \mathrm{~mm}$ s.d $26 \mathrm{~mm}$, dilakukan perubahan dengan memperkecil ampere, namun menaikan frekuensi dengan maksud mengurangi panas pada ujung elektroda. Panas yang berlebih pada ujung elektroda sebagai akibat dari besarnya ampere akan mempercepat keausan ujung elektroda ( $\mathrm{Li}$ et al. 2014).

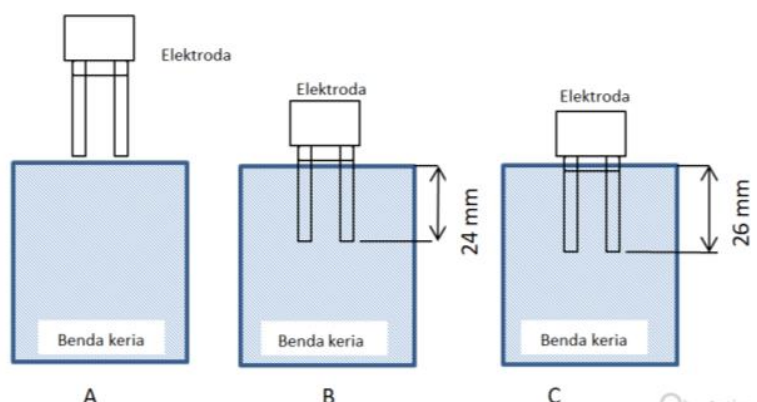

Gambar 5. Strategi proses EDM

Sumber : (Maradia et al. 2012), diolah peneliti

Pada Gambar 5A dijelaskan kondisi awal, pada Gambar 5B strategi proses EDM dengan parameter (1) ampere $8 A ; T_{\text {on }} 20 \mu s ; T_{\text {off }}$ $10 \mu \mathrm{s}$. pada kedalaman 0 - $24 \mathrm{~mm}$ dan Gambar 5C dengan parameter (2) ampere $6 A ; T_{\text {on }} 3 \mu \mathrm{s}$, $T_{\text {off }} 4 \mu \mathrm{s}$ pada kedalamam 24 -. $26 \mathrm{~mm}$.

\section{KESIMPULAN}

Berdasarkan hasil pengumpulan data, proses EDM pada pembuatan profil pocket untuk komponen core cavity dengan menggunakan elektroda tembaga yang mempunyai ketebalan $2 \mathrm{~mm}$ dengan kedalaman $26 \mathrm{~mm}$, maka strategi proses EDM yang dilakukan yaitu (1) pada kedalaman $0-24 \mathrm{~mm}$ yaitu proses roughing dengan parameter ampere $8 \mathrm{~A} ; T_{\text {on }} 20 \mu \mathrm{s} ; T_{\text {off }} 10 \mu \mathrm{s}$. (2) proses selanjutnya dikategorikan sebagai proses finishing pada kedalaman 24 - 26 mm menggunakan parameter ampere $6 \mathrm{~A} ; T_{\text {on }} 3 \mu \mathrm{s}, T_{\text {off }} 4 \mu \mathrm{s}$. Dengan menggunakan strategi dua parameter pada kedalaman berbeda, dapat mengurangi keausan elektroda dan memperpanjang umur penggunaan elektroda. Setting parameter diatas yang telah dilakukan pada penelitian ini, mungkin akan berbeda pada kondisi proses EDM yang lain. Untuk itu disarankan perlunya penelitian lanjutan pada proses EDM lainnya dengan memperhitungkan faktor-faktor seperti : ketebalan dan bentuk elektroda, jenis material benda kerja, jenis material elektroda, jenis dielectric fluid yang digunakan, dst. 


\section{UCAPAN TERIMA KASIH}

Ucapan terima kasih kepada Bapak Pujiyanto dan Bapak Hafid dari MIDC serta Bapak Rohimat dari CV. Mediatek yang telah membantu menfasilitasi pengumpulan data serta memberikan diskusi yang bermanfaat pada penelitian ini.

\section{DAFTAR PUSTAKA}

CHMER. 2012. "CHMER Features of CNC Series Electricity Function." Taichung Taiwan.

Fan, Yinsheng, Jicheng Bai, Qiang Li, Chaojiang Li, Yan Cao, and Zhengkai Li. 2016. "Research on Maintaining Voltage of Spark Discharge in EDM." Procedia CIRP 42 (Isem Xviii). Elsevier B.V.: 2833. doi:10.1016/j.procir.2016.02.180.

Guo, Y, and Z Ling. 2016. "A Magnetic Suspension Spindle System for Micro EDM." Procedia CIRP 42 (Isem Xviii). Elsevier B.V.: 543-46. doi:10.1016/j.procir.2016.02.248.

Li, Xiao-peng, Yuan-gang Wang, Fu-ling Zhao, Meng-hua $\mathrm{Wu}$, and $\mathrm{Yu}$ Liu. 2014. "ScienceDirect Influence of High Frequency Pulse on Electrode Wear in Micro-EDM.” Defence Technology 10 (3). Elsevier Ltd: 316-20. doi:10.1016/j.dt.2014.07.007.

Maradia, U, M Boccadoro, J Stirnimann, I Beltrami, F Kuster, and K Wegener. 2012. "Die-Sink EDM in Meso-Micro Machining" 1: 166-71. doi:10.1016/j.procir.2012.04.029.
Patel, Narendra Kumar. 2014. "Parametric Optimization of Process Parameters For EDM of Stainless Steel 304 Narendra Kumar Patel National Institute of Technology Rourkela," no. May.

Rajmohan T., Prabhu R., Subba Rao G., Palanikumar K., B. 2012. "Optimization of Machining Parameters in Electrical Discharge Machining (EDM) of 304 Stainless Steel" 38: 1030-36. doi:10.1016/j.proeng.2012.06.129.

Risto, M, R Haas, and M Munz. 2016. "Optimization of the EDM Drilling Process to Increase the Productivity and Geometrical Accuracy." Procedia CIRP 42 (Isem Xviii). Elsevier B.V.: 537-42. doi:10.1016/j.procir.2016.02.247.

Shailesh Kumar Dewangan. 2010. "Experimental Investigation of Machining Parameters for EDM Using U-Shaped Electrode of AISI P20 Tool Steel." Master Thesis of Department of Mechanical Engineering National Institute of Technology Rourkela (India).

Zhang, Min, Qinhe Zhang, Guang Zhu, Qingyu Liu, and Jianhua Zhang. 2016. "Effects of Some Process Parameters on the Impulse Force in Single Pulsed." Procedia CIRP 42 (Isem Xviii). Elsevier B.V.: 627-31. doi:10.1016/j.procir.2016.02.260. 